\title{
Geographic, demographic, and socioeconomic variations in the investigation and management of coronary heart disease in Scotland
}

\author{
M C M MacLeod, A R Finlayson, J P Pell, I N Findlay
}

\begin{abstract}
Objective-To determine whether age, sex, level of deprivation, and area of residence affect the likelihood of investigation and treatment of patients with coronary heart disease.

Design, patients, and interventionsRoutine discharge data were used to identify patients admitted with acute myocardial infarction (AMI) between 1991 and 1993 inclusive. Record linkage provided the proportion undergoing angiography, percutaneous transluminal coronary angioplasty (PTCA), and coronary artery bypass grafting (CABG) over the following two years. Multiple logistic regression analysis was used to determine whether age, sex, deprivation, and area of residence were independently associated with progression to investigation and revascularisation.
\end{abstract}

Setting-Mainland Scotland 1991 to 1995 inclusive.

Main outcome measures-Two year incidence of angiography, PTCA, and CABG. Results-36 838 patients were admitted with AMI. 4831 (13\%) underwent angiography, 587 (2\%) PTCA, and 1825 (5\%) CABG. Women were significantly less likely to undergo angiography $(p<0.001)$ and CABG ( $p<0.001)$ but more likely to undergo PTCA $(p<0.05)$. Older patients were less likely to undergo all three procedures $(p<0.001)$. Socioeconomic deprivation was associated with a reduced likelihood of both angiography and CABG $(p<0.001)$. There were significant geographic variations in all three modalities $(\mathrm{p}<0.001)$.

Conclusion-Variations in investigation and management were demonstrated by age, sex, geography, and socioeconomic deprivation. These are unlikely to be accounted for by differences in need; differences in clinical practice are, therefore, likely.

(Heart 1999;81:252-256)

Keywords: geographic variations; socioeconomic deprivation; coronary revascularisation; ischaemic heart disease; epidemiology

Coronary heart disease (CHD) is the most common cause of death in Scotland in both men and women, accounting for more than a quarter of all deaths. ${ }^{12}$ However, there are wide variations in CHD mortality rates within
Information and

Statistics Division, Scottish Health Service, Edinburgh, UK

M C M MacLeod

A R Finlayson

Greater Glasgow

Health Board,

Glasgow, UK

J P Pell

Royal Alexandra Hospital, Paisley, UK

I N Findlay

Correspondence to: Dr I Findlay, Royal Alexandra Hospital, Corsebar Road, Paisley, Renfrewshire PA2 9PN, UK

Accepted for publication 9 October 1998

Table 1 Numbers and crude percentages of patients admitted with an AMI who subsequently underwent angiography, $P T C A$, and $C A B G$ within two years by age group, sex, deprivation category, and health board area of residence

\begin{tabular}{|c|c|c|c|c|c|c|c|}
\hline & $\begin{array}{l}\text { AMI } \\
\text { admissions }\end{array}$ & $\begin{array}{l}\text { Angiography } \\
n(\%)\end{array}$ & p value & $\begin{array}{l}P T C A \\
n(\%)\end{array}$ & p value & $\begin{array}{l}C A B G \\
n(\%)\end{array}$ & $p$ value \\
\hline Age group $\star$ & & & $<0.0001$ & & $<0.0001$ & & $<0.0001$ \\
\hline$<50$ years & 3110 & $1191(38)$ & & $188(6)$ & & $324(10)$ & \\
\hline $50-59$ years & 6504 & $1733(27)$ & & $205(3)$ & & $680(11)$ & \\
\hline $60-69$ years & 10519 & $1493(14)$ & & $160(2)$ & & $668(6)$ & \\
\hline$\geqslant 70$ years & 16705 & $414(3)$ & & $34(0)$ & & $153(1)$ & \\
\hline Sex† & & & $<0.0001$ & & $<0.001$ & & $<0.0001$ \\
\hline Male & 21925 & $3645(17)$ & & $405(2)$ & & $1394(6)$ & \\
\hline Female & 14913 & $1186(8)$ & & $182(1)$ & & $431(3)$ & \\
\hline Deprivation category ( 1 is & & & & & & & \\
\hline least deprived $)^{\star}$ & & & NS & & NS & & NS \\
\hline 1 & 1694 & $280(17)$ & & $30(2)$ & & $101(6)$ & \\
\hline 2 & 4416 & $618(14)$ & & $73(2)$ & & $249(6)$ & \\
\hline 3 & 7616 & $980(13)$ & & $127(2)$ & & $359(5)$ & \\
\hline 4 & 9344 & $1115(12)$ & & $147(2)$ & & $383(4)$ & \\
\hline 5 & 6099 & $806(13)$ & & $100(2)$ & & $297(5)$ & \\
\hline 6 & 4597 & $590(13)$ & & $63(1)$ & & $270(6)$ & \\
\hline 7 & 2740 & $408(15)$ & & $42(2)$ & & $156(6)$ & \\
\hline Missing & 324 & 34 & & 5 & & 10 & \\
\hline Health board of residence & & & $<0.001$ & & $<0.001$ & & $<0.001$ \\
\hline Argyll \& Clyde & 3353 & $411(12)$ & & $49(2)$ & & $184(6)$ & \\
\hline Ayrshire \& Arran & 2784 & $237(9)$ & & $30(1)$ & & $113(4)$ & \\
\hline Borders & 799 & $105(13)$ & & $11(1)$ & & $35(4)$ & \\
\hline Dumfries \& Galloway & 1211 & $103(9)$ & & $8(1)$ & & $50(4)$ & \\
\hline Fife & 2294 & $196(9)$ & & $32(1)$ & & $73(3)$ & \\
\hline Forth Valley & 1983 & $254(13)$ & & $42(2)$ & & $110(6)$ & \\
\hline Grampian & 3175 & $603(19)$ & & $42(1)$ & & $183(6)$ & \\
\hline Greater Glasgow & 6790 & $943(14)$ & & $88(1)$ & & $403(6)$ & \\
\hline Highland & 1376 & $189(14)$ & & $24(2)$ & & $63(5)$ & \\
\hline Lanarkshire & 4095 & $498(12)$ & & $70(2)$ & & $207(5)$ & \\
\hline Lothian & 5305 & $845(16)$ & & $150(3)$ & & $222(4)$ & \\
\hline Tayside & 3673 & $447(12)$ & & $41(1)$ & & $182(5)$ & \\
\hline
\end{tabular}

*Significance tested by $\chi^{2}$ test for trend; †significance tested by $\chi^{2}$ test. 
Table 2 Age stratified sex specific percentages of AMI admissions followed within two years by angiography, PTCA, and $C A B G$

\begin{tabular}{|c|c|c|c|c|c|c|c|c|}
\hline \multirow[b]{2}{*}{ Age groups } & \multicolumn{2}{|c|}{ AMI admissions } & \multicolumn{2}{|l|}{ Angiography } & \multicolumn{2}{|l|}{ PTCA } & \multicolumn{2}{|l|}{$C A B G$} \\
\hline & Male (n) & Female (n) & Male $n(\%)$ & $\begin{array}{l}\text { Female } \\
n(\%)\end{array}$ & $\begin{array}{l}\text { Male } \\
n(\%)\end{array}$ & $\begin{array}{l}\text { Female } \\
n(\%)\end{array}$ & Male $n(\%)$ & $\begin{array}{l}\text { Female } \\
n(\%)\end{array}$ \\
\hline$<50$ & 2571 & 539 & 989 (39) & $202(38)$ & $145(6)$ & $43(8)$ & $291(11)$ & $33(6)$ \\
\hline $50-59$ & 4805 & 1699 & $1340(28)$ & $393(23)$ & $142(3)$ & $63(4)$ & $538(11)$ & $142(8)$ \\
\hline $60-69$ & 6770 & 3749 & $1064(16)$ & $429(11)$ & $101(2)$ & $59(2)$ & $464(7)$ & $204(5)$ \\
\hline$\geqslant 70$ & 7779 & 8926 & 252 (3) & $162(2)$ & $17(0)$ & $17(0)$ & $101(1)$ & $52(1)$ \\
\hline
\end{tabular}

Scotland, with rates tending to be highest in the west of the country. These geographic variations can probably be attributed to different levels of risk factors such as smoking, diet, and deprivation. ${ }^{34}$

Rates of revascularisation procedures are largely dependent on rates of angiography. ${ }^{5-8}$ Several studies have demonstrated variations in the general population rates of both angiography and revascularisation procedures by area of residence, ${ }^{9}$ sex $^{6-8}$ and level of deprivation. ${ }^{10-13}$ However, in interpreting these results cognisance must be taken of variations in the underlying incidence of disease. A number of these studies used CHD mortality as a proxy measure of incidence and generally failed to demonstrate any association between mortality and procedure rates. This suggests that the variations observed in practice cannot be attributed to variations in need and, therefore, raises the possibility of inequalities in care. However, in using mortality as a proxy measure of incidence, account must be taken of possible variations in coding and accuracy of diagnosis. Furthermore, mortality is a proxy of community incidence and, as such, takes no account of variations in the threshold for referral of CHD patients to hospital physicians. Therefore, it is difficult to determine the extent to which differences in procedure rates which are not accounted for by differences in mortality can be attributed to variations in cardiology practice.

An alternative method is to examine investigation and treatment rates in those patients presenting to hospital with definite CHD. The numbers and severity of elective CHD admissions are dependent on referral thresholds and waiting times. Therefore, acute myocardial infarction (AMI) admissions provide a better proxy measure of the hospital incidence of CHD requiring invasive investigation.

This study examined angiography, percutaneous transluminal coronary angioplasty (PTCA), and coronary artery bypass grafting (CABG) rates following admission for AMI and the extent to which these varied by age, sex, socioeconomic deprivation level, and area of residence.

\section{Methods}

Discharge data are routinely collected on all patients admitted to Scottish hospitals using the Scottish morbidity record (SMR1). This collects information on age, sex, postcode, health board area of residence, disease code, and procedures undertaken. Diagnosis and procedure accuracy have been demonstrated to be $90 \%$ and $91 \%$, respectively. ${ }^{14}$

Table 3 Multiple logistic regression analysis of the factors associated with progression to angiography, PTCA, and CABG within two years of an admission for $A M I$

\begin{tabular}{|c|c|c|c|c|c|c|}
\hline \multirow[b]{2}{*}{ Predictor variable } & \multicolumn{2}{|l|}{ Angiography } & \multicolumn{2}{|l|}{ PTCA } & \multicolumn{2}{|l|}{$C A B G$} \\
\hline & Odds ratio $(95 \%$ CI) & $p$ value & Odds ratio $(95 \%$ CI) & p value & Odds ratio $(95 \%$ CI) & $p$ value \\
\hline \multicolumn{7}{|l|}{ Sex } \\
\hline Male & 1.00 & & 1.00 & & 1.00 & \\
\hline Female & $0.73(0.68$ to 0.79$)$ & $<0.001$ & $1.21(1.01$ to 1.46$)$ & $<0.05$ & $0.68(0.61$ to 0.77$)$ & $<0.001$ \\
\hline \multicolumn{7}{|l|}{ Age (years) } \\
\hline$<50^{\star}$ & 1.00 & & 1.00 & & 1.00 & \\
\hline 50 to 59 & $0.60(0.56$ to 0.66$)$ & $<0.001$ & $0.51(0.41$ to 0.62$)$ & $<0.001$ & $1.03(0.90$ to 1.19$)$ & NS \\
\hline 60 to 69 & $0.27(0.25$ to 0.30$)$ & $<0.001$ & $0.23(0.19$ to 0.29$)$ & $<0.001$ & $0.62(0.54$ to 0.71$)$ & $<0.001$ \\
\hline$\geqslant 70$ & $0.04(0.04$ to 0.05$)$ & $<0.001$ & $0.29(0.02$ to 0.04$)$ & $<0.001$ & $0.09(0.07$ to 0.11$)$ & $<0.001$ \\
\hline \multicolumn{7}{|c|}{ Deprivation category ( 1 is least deprived) } \\
\hline $1^{\star}$ & 1.00 & & 1.00 & & 1.00 & \\
\hline 2 & $0.89(0.75$ to $1 / 06)$ & NS & $1.00(0.65$ to 1.56$)$ & NS & $1.04(0.82$ to 1.34$)$ & NS \\
\hline 3 & $0.84(0.71$ to 0.99$)$ & $<0.05$ & $0.95(0.62$ to 1.44$)$ & NS & $0.85(0.67$ to 1.08$)$ & NS \\
\hline 4 & $0.70(0.60$ to 0.83$)$ & $<0.001$ & $0.77(0.51$ to 1.16$)$ & NS & $0.70(0.55$ to 0.89$)$ & $<0.01$ \\
\hline 5 & $0.77(0.65$ to 0.91$)$ & $<0.01$ & $0.76(0.50$ to 1.17$)$ & NS & $0.80(0.62$ to 1.01$)$ & NS \\
\hline 6 & $0.75(0.63$ to 0.89$)$ & $<0.01$ & $0.73(0.47$ to 1.16$)$ & NS & $0.87(0.68$ to 1.12$)$ & NS \\
\hline 7 & $0.70(0.58$ to 0.85$)$ & $<0.05$ & $0.70(0.43$ to 1.16$)$ & NS & $0.70(0.53$ to 0.92$)$ & $<0.01$ \\
\hline \multicolumn{7}{|l|}{ Health board of residence } \\
\hline Argyll \& Clyde & 1.00 & & 1.00 & & 1.00 & \\
\hline Ayrshire \& Arran & $0.66(0.55$ to 0.78$)$ & $<0.001$ & 0.77 (0.46 to 1.22$)$ & NS & $0.73(0.57$ to 0.94$)$ & $<0.05$ \\
\hline Borders & $1.38(1.07$ to 1.77$)$ & $<0.05$ & $1.10(0.56$ to 2.16$)$ & NS & $0.92(0.62$ to 1.34$)$ & NS \\
\hline Dumfries \& Galloway & $0.70(0.55$ to 0.89$)$ & $<0.01$ & $0.48(0.22$ to 1.02$)$ & NS & $0.78(0.56$ to 1.08$)$ & NS \\
\hline Fife & $0.67(0.55$ to 0.81$)$ & $<0.001$ & $0.98(0.62$ to 1.55$)$ & NS & $0.59(0.45$ to 0.79$)$ & $<0.001$ \\
\hline Forth Valley & $1.07(0.90$ to 1.29$)$ & NS & $1.45(0.95$ to 2.22$)$ & NS & $1.05(0.82$ to 1.35$)$ & NS \\
\hline Grampian & $2.01(1.73$ to 2.34$)$ & $<0.001$ & $0.94(0.61$ to 1.45$)$ & NS & $1.10(0.89$ to 1.38$)$ & NS \\
\hline Greater Glasgow & $1.24(1.08$ to 1.42$)$ & $<0.01$ & $0.95(0.65$ to 1.38$)$ & NS & $1.15(0.95$ to 1.40$)$ & NS \\
\hline Highlands & $1.17(0.96$ to 1.43$)$ & NS & $1.15(0.69$ to 1.91$)$ & NS & $0.86(0.64$ to 1.17$)$ & NS \\
\hline Lanarkshire & $0.89(0.77$ to 1.03$)$ & NS & $1.09(0.75$ to 1.58$)$ & NS & 0.85 (0.69 to 1.05$)$ & NS \\
\hline Lothian & $1.55(1.35$ to 1.78$)$ & $<0.001$ & $2.12(1.51$ to 2.96$)$ & $<0.001$ & $0.82(0.66$ to 1.01$)$ & NS \\
\hline Tayside & $1.16(0.99$ to 1.35$)$ & NS & $0.87(0.57$ to 1.32$)$ & NS & $0.99(0.79$ to 1.22$)$ & NS \\
\hline
\end{tabular}

^Reference categories. 
The data collected by individual hospitals are collated by the Information and Statistics Division (ISD) of the Scottish Health Service. Record linkage permits all SMR1 records relating to one patient to be identified, thereby allowing information to be obtained on subsequent admissions and procedures following discharge. ${ }^{15}$

Postcode of residence can be used to attribute a Carstairs deprivation category to the 5000 or so people resident within that postcode area. ${ }^{16}$ The categories are derived from 1991 census data on the proportion of residents who are unemployed, live in overcrowded accommodation, do not have access to a car, or belong to a low occupational social class. There are seven categories with category 1 representing the least deprived section of the population and category 7 the most deprived. Application of the scores to patients can demonstrate socioeconomic bias in the selection of patients for admission or procedures.

Scotland is divided into 15 health board areas. However, the three island boards are very sparsely populated and, therefore, very small numbers of procedures are undertaken on their residents. Hence this study was restricted to the 12 mainland boards.

The linked SMR1 dataset was used to identify Scottish residents who were admitted to hospital for AMI (ninth revision of the International Classification of Diseases (ICD9) 410) between 1991 and 1993 inclusive. The AMI admissions were broken down in terms of age, sex, deprivation category, and health board area of residence. The numbers of these patients who were readmitted for angiography (OPCS4 K63, K65), PTCA (OPCS4 K49), and CABG (OPCS4 K40-K48) within two years of this admission was also obtained. Two years was used to accommodate the waiting times in existence at that time.

The association between age, sex, deprivation category, and health board area of residence and the percentage of AMI patients who progressed to angiography or revascularisation was determined univariately using $\chi^{2}$ tests and $\chi^{2}$ tests for trend. The extent to which these associations were independent of each other was then tested using multivariate logistic regression analysis.

\section{Results}

Over the three year period 36838 patients were admitted to hospital with a diagnosis of AMI. Of these, 21925 (60\%) were male and $14913(40 \%)$ were female. Their median age was 68 years and $20 \%$ belonged to the lowest two deprivation categories. Overall, 4831 $(13 \%)$ underwent angiography within two years, $587(2 \%)$ underwent PTCA, and 1825 (5\%) CABG.

On univariate analysis, there were significant trends across the age groups for the use of both angiography and revascularisation procedures $\left(\chi^{2}\right.$ for trend, $\left.p<0.0001\right)$, with older patients undergoing lower rates of all interventions (table 1). Similarly, women had significantly lower rates of all three modalities $\left(\chi^{2}\right.$, $\mathrm{p}<0.0001$ ) (table 1). However, age and sex



Figure 1 Age, sex, and deprivation category standardised percentages of admissions for $A M I$ which were followed by angiography, $P T C A$, or $C A B G$ within two years by health board area of residence. For names of health boards see table 1.

themselves were related, with women tending to be admitted at an older age than men. Stratification by age produced more comparable rates between the sexes (table 2). There were no significant univariate associations between deprivation category and any of the procedures (table 1).

Variations were demonstrated between health board area of residence (table 1). There was a twofold variation in the crude percentages of AMI patients progressing to angiography and CABG ( $p<0.001)$, and a threefold difference in those undergoing PTCA $(\mathrm{p}<0.001)$.

On multiple logistic regression analysis women were significantly less likely to undergo angiography $(\mathrm{p}<0.001)$ and CABG $(\mathrm{p}<0.001)$ but more likely to undergo PTCA $(\mathrm{p}<0.05)$ (table 3$)$. Older patients were less likely to undergo all three interventions $(\mathrm{p}<0.001)$. Unlike on univariate analysis, socioeconomic deprivation was associated with a reduced likelihood of both angiography and CABG ( $p<0.001)$ but not PTCA. There were significant geographical variations in all three modalities $(p<0.001)$ (fig 1$)$. 


\section{Discussion}

Variations in crude population procedure rates can be difficult to interpret since they may be justified if associated with variations in incidence, risk, or benefit. The incidence of CHD is known to vary by age, sex, area of residence, and deprivation level. Therefore, comparisons within these categories must take account of incidence.

A number of studies have attempted to overcome this problem by using CHD mortality rates as a proxy measure of incidence, and comparing variations in procedure rates with variations in mortality rates. However, CHD mortality rates include patients dying outside hospital for whom coding of the cause of death is likely to be less accurate. Furthermore, mortality is a proxy measure of the community incidence of CHD rather than the hospital incidence. The latter is dependent not only on community incidence but also referral patterns, and it would be inappropriate to hold hospital physicians accountable for the management of those patients who are not known to them.

Therefore, new patients referred to hospital with definite CHD may be a more appropriate denominator for comparing hospital practice. In this study, this was further refined to AMI admissions because of the lack of consistency in applying other CHD codes, and the fact that elective admissions reflect referral thresholds and waiting times as much as they do incidence. A minority of AMI patients have normal coronary arteries but such patients would also be included if a clinical history of angina or a positive exercise test were used to identify CHD patients.

The results of this study provide evidence that the variations in provision of cardiac investigations and treatments across Scotland cannot be fully explained by variations in need. Compared with other countries, primary PTCA is a relatively uncommon procedure in all Scottish hospitals. Therefore the variations observed relate primarily to the management of patients with chronic stable angina and unstable angina.

Older CHD patients were demonstrated to be significantly less likely to be both investigated and treated after adjustment for sex, socioeconomic status, and area of residence. This supports the findings of previous studies. ${ }^{17}$ This may reflect a belief that revascularisation procedures pose a greater risk in these patients or that their benefit is reduced. A number of studies have demonstrated higher early mortality rates following revascularisation, ${ }^{18-20}$ although these findings are not unanimous. ${ }^{21}$ Older patients can nonetheless gain significant symptomatic benefit from revascularisation. ${ }^{18}{ }^{22}$

On univariate analysis women were significantly less likely to be investigated than men. However, there was a clear association between sex and age with the peak number of women admitted for AMI occurring 10 years after that in men, and age stratified procedures rates were relatively comparable between the sexes. Nonetheless, adjustment for age, deprivation, and area of residence in the multivariate analysis revealed a significant independent association between sex and access to angiography and CABG. Other studies have similarly demonstrated lower rates of angiography and revascularisation in women, ${ }^{6-9}$ even at comparable levels of morbidity. ${ }^{23}$ Lower CABG rates in women with CHD may be justified by their lower rate of severe stenoses, ${ }^{8}$ the fact that they have relatively low rates of CHD mortality compared with angina, ${ }^{24}$ and their higher use of PTCA. However, lower angiography rates are more difficult to explain in light of women tending to have more severe symptoms and greater functional disability than men. ${ }^{6}$

As with other studies, ${ }^{10-1325}$ socioeconomic deprivation was demonstrated to be associated with reduced access to angiography and CABG. The lack of a significant association with PTCA is likely to reflect the smaller numbers of patients undergoing this procedure, since the odds ratios nonetheless showed a clear trend across deprivation categories.

Significant geographical variations were demonstrated for all three modalities. Previous studies have also demonstrated geographical variations which cannot be explained by need. ${ }^{9-11} 26$ These differences can, in part, be attributed to ease of access, with patients resident close to facilities most likely to be referred to them. ${ }^{9-11}$

Because PTCA and CABG are both preceded by angiography, variations in angiography tend to perpetuate as variations in revascularisation..$^{5-8}$ Therefore, access to angiography needs to be addressed before variations in revascularisation can be reduced.

Variations in practice can reflect both unnecessary interventions and unmet need. Studies from England and the USA have suggested that $25-50 \%$ of angiograms may be inappropriate. ${ }^{27}{ }^{28}$ However, the much higher prevalence of CHD in Scotland means that a comparable level of over provision is unlikely to be the case. In light of Scotland having one of the highest rates of CHD deaths in the world,,$^{29}$ it is likely that much of the demonstrated variation in practice reflects unmet need in some areas.

1 Health Policy and Public Health Directorate. Coronary heart disease in Scotland. Edinburgh: SOHHD, 1995.

2 World Health Statistics. Geneva: World Health Organisation, 1994.

3 Logan RL, Riemersma RA, Thomson M, et al. Risk factors for ischaemic heart disease in normal men aged 40 . Edinburgh-Stockholm study. Lancet 1978;i:949-54.

4 Smith WCS, Shewry MC, Tunstall-Pedoe H, et al. Cardiovascular disease in Edinburgh and north Glasgow-a tale of two cities. F Clin Epidemiol 1990;42:637-43.

5 Elder AT, Shaw TRD, Turnbull C, et al. Elderly and younger patients selected to undergo coronary angioyounger patients selected to
graphy. $B M \mathcal{F} 1991 ; \mathbf{3 0 3}: 950-3$.

6 Steingart RM, Packer M, Hamm P, et al. Sex differences in Steingart RM, Packer M, Hamm P, et al. Sex differences in
the management of coronary artery disease. $N$ Engl $\mathcal{F}$ Med 1991;324:226-30.

7 Ayanian JZ, Epstein AM. Differences in the use of procedures between women and men hospitalised for coronary disease. N Engl f Med 1991;325:221-5.

8 Kromholz H, Douglas P, Lauer M, et al. Selection of patients for coronary angiography and coronary revascularisation after myocardial infarction: is there evidence for a gender bias? Ann Intern Med 1992;166:785-90.

9 Kee F, Gaffney B, Currie S, et al. Access to coronary Kee F, Gaffney B, Currie S, et al. Access to coronary
catheterisation: fair shares for all? BMf 1993;307:1305-7.

10 Findlay IN, Dargie HJ, Dyke T, et al. Who gets coronary angiography in Scotland? Br Heart $\mathcal{F} 1990 ; 64: 43-4$. 
11 Findlay IN, Dargie JH, Dyke T. Coronary angiography in Glasgow: relation to coronary heart disease and social class. Br Heart f 1991;66:A70.

12 Gittelsohn AM, Halalpern J, Sanchez RL. Income, race, and surgery in Maryland. Am $\mathcal{F}$ Public Health 1991;81:1435-41.

13 Payne N, Saul C. Variations in use of cardiology services in a health authority: comparison of coronary artery revascularisation rates with prevalence of angina and coronary mortality. BMF 1997;314:257-61.

14 Harley K, Jones C. Quality of Scottish morbidity record (SMR) data. Health Bull 1996;54:410-17.

15 Kendrick S, Clarke J. The Scottish record linkage system. Health Bull 1993;51:72-9.

16 Carstairs V, Morris R. Deprivation and health in Scotland. Aberdeen: Aberdeen University Press, 1991.

17 Bearden D, Allman R, McDonald R, et al. Age, race and gender variation in the utilization of coronary artery bypass surgery and angiogplasty in SHEP. $f \mathrm{Am}$ Geriatr Soc 1994; 42:1143-9.

18 Ivert T, Lindblom D, Welti R. Coronary artery bypass grafting in patients 70 years of age and older: early and late ing in patients 70 years of age and older: earl
results. Eur $\mathcal{F}$ Cardiothorac Surg 1989;3:52-7.

19 Hannan EL, Burke J. Effect of age on mortality in coronary artery bypass surgery in New York, 1991-1992. Am Heart f 1994;128:1184-91.

20 Rose DM, Gelbfish J, Jacobowitz IJ, et al. Analysis of morbidity and mortality in patients 70 years of age and over undergoing isolated coronary artery bypass surgery. $A m$ Heart $\mathcal{f} 1985 ; 110: 341-6$.
21 Johnston FA, Spyt T, Reece I, et al. CABG in the elderly: the Glasgow experience. Gerontology 1989;35:165-70.

22 Morgan JM, Gray HH, Clague JC, et al. Coronary arterial surgery in the elderly: its effect in the relief of angina. Int $\mathcal{F}$ Cardiol 1989:23:327-3.

23 Pettigrew M, McKee M, Jones J. Coronary artery surgery: are women discrimated against? BMF 1993;306:1164-6.

24 Harris RB, Weissfeld LA. Gender differences in the reliability of reporting symptoms of angina pectoris. $\mathcal{F}$ Clin Epidemiol 1991;44:1071-8.

25 Keskimaki I, Koskinen S, Salinto M, et al. Socioeconomic and gender inequities in access to coronary artery bypass
grafting in Finland. Eur F Public Health 1997;7:392-7.

26 Black N, Langham S, Coshall C, et al. Impact of the 1991 NHS reforms on the availability and use of coronary revascularisation in the UK (1987-1995). Heart 1996;76 (supp 4): $1-29$.

27 Graboys TB, Biegelsen B, Lampert S, et al. Results of a second-opinion trial among patients recommended for coronary angiography. $\mathcal{F A M A}$ 1992;268:2537-40.

28 Gray D, Hampton JR. Methods of establishing criteria for purchasing coronary angiography in the investigation of chest pain. F Public Health 1994;16:399-405.

29 Smith WCS, Kenicer MB, Tunstall-Pedoe H, et al. Prevalence of coronary heart disease in Scotland: Scottish heart health study. Br Heart f 1990;64:295-8.

30 Tunstall-Pedoe H, Smith WCS, et al. Levels and trends of cornary heart disease mortality in Scotland compared with other countries. Health Bull 1986;44:153-61. 